\section{First report of Eutropis innotata (Blanford, 1870) (Reptilia: Scincidae) from Nallamalai Hills, Andhra Pradesh, India}

\author{
K. Thulsi Rao ${ }^{1}$, S.M. Maqsood Javed ${ }^{2,4} \&$ \\ C. Srinivasulu ${ }^{3}$
}

${ }^{1}$ Eco-Research and Monitoring Laboratories, Nagarjunasagar Srisailam Tiger Reserve, Sundipenta, Kurnool District, Andhra Pradesh 518102, India

${ }^{2}$ WWF-India, Andhra Pradesh State Office, 818, Castle Hills, Near NMDC, Vijaynagar Colony, Hyderabad, Andhra Pradesh 500057, India

${ }^{3}$ Wildlife Biology Section, Department of Zoology, University College of Science, Osmania University, Hyderabad, Andhra Pradesh 500007, India

Email: ${ }^{4}$ javedwwf2007@gmail.com (corresponding author)

The genus Mabuya Fitzinger, 1826 was recently revised by Mausfeld et al. (2002) and suggested partitioning the genus into several genera, allocating the Asian species to Eutropis Fitzinger, 1843. In India, the genus Eutropis is represented by 18 species (Das 1996; Sharma 2002). Out of these, only four species [excluding Mabuya aurata (Linnaeus, 1758) = Trachylepis aurata aurata (Linnaeus, 1758) (Bauer, 2003)], namely, Eutropis bibronii (Gray, 1839); Eutropis dissimilis (Hallowell, 1857); Eutropis innotata (Blanford, 1870); Eutropis novemcarinata (Anderson, 1871) are known from India to possess, more or less, transparent disc on the lower eye lid. In Andhra Pradesh, the genus is represented by Eutropis carinata,

Date of publication (online): 26 January 2010

Date of publication (print): 26 January 2010

ISSN $0974-7907$ (online) | 0974-7893 (print)

Editor: S. Bhupathy

Manuscript details:

Ms \# 02087

Received 23 October 2008

Final received 05 January 2010

Finally accepted 09 January 2010

Citation: Rao, K.T., S.M.M. Javed \& C. Srinivasulu (2010). First report of Eutropis innotata (Blanford, 1870) (Reptilia: Scincidae) from Nallamalai Hills, Andhra Pradesh, India. Journal of Threatened Taxa 2(1): 666-669.

Copyright: (c) K. Thulsi Rao, S.M. Maqsood Javed \& C. Srinivasulu 2010. Creative Commons Attribution 3.0 Unported License. JoTT allows unrestricted use of this article in any medium for non-profit purposes, reproduction and distribution by providing adequate credit to the authors and the source of publication.

Acknowledgments: The authors are very much thankful to Shri K.S. Rao, IFS, Prl. Chief Conservator of Forests, Shri Hitesh Malhotra, IFS, Prl. Chie Conservator of Forest (Wildlife) and Chief Wildlife Warden, Shri Sunil Kumar, IFS, Addl. Prl. Chief Conservator of Forest (Wildlife) and Shri A.K. Nayak, IFS, Conservator of Forests \& Field Director, Nagarjunasagar-Srisailam Tiger Reserve for constant encouragement and sustained support. We are also grateful to Dr. Rajesh Gopal, IFS, Inspector General of Forests, Ministry of Environment and Forests for funding support and encouragements. SMMJ expresses gratitude to Shri Anil Kumar V. Epur, Chairman, WWF-AP State Committee, Shri Ravi Singh, SG \& CEO, WWF-India, New Delhi and Ms. Farida Tampal, State Director and National Coordinator, EPCG, WWF-India, AP State Office, Hyderabad for constant support and encouragement. CS acknowledges CSIR, New Delhi for funding and Head, Department of Zoology, Osmania University, Hyderabad for encouragement. We also thank Dr. Hemant V. Ghate, Modern College, Pune and Dr. Aaron M. Bauer, Villanova University, USA for helping in identification and constructive suggestions.

OPEN ACGESS | FREE DOWNLOAD
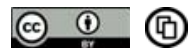

Eutropis macularia and Eutropis nagarjuni (Sanyal et al. 1993; Sharma 2002; Rao et al. 2005; Srinivasulu \& Das 2008). During 2002-2004 faunal surveys, we recorded a total of 48 species of reptiles including three known species of skinks (E. carinata, E. macularia and E. nagarjuni) from Nallamalai Hills, Andhra Pradesh (Rao et al. 2005; Srinivasulu et al. 2005). However, one of the specimens (ERMR-45a = RS-4B, Images 1 \& 2) belonging to the genus Eutropis collected from the Chinnamanthanala (15053'N \& 7846'E), Gundla Brahmeswaram Metta Sanctuary (GBM), Prakasam District (Image 1) on 02 May 2002 remained unidentified. In 2008 we examined this specimen deposited at the Ecological Research and Monitoring Laboratories (ERM Labs), Sundipenta and identified it as Eutropis innotata (Blanford, 1870). It is a rare, Data Deficient and endemic species to central India (Molur \& Walker 1998; Sharma 2002) and is known from only a few localities (Sharma 2002; Chandra \& Gajbe 2005). Through this paper, we report the occurrence of Eutropis innotata in the Nallamalai Hills, Eastern Ghats, Andhra Pradesh and put on record range extension of this species further south in peninsular India.

Diagnosis: Eutropis innotata distinctly differs from other congeneric species from India as follows: Supranasals separated (vs. separated or just touching one another in $E$. bibronii; in contact with one another in $E$. dissimilis and $E$. novemcarinata); a single pair of smooth nuchals present (vs. two pairs of multi-keeled in E. bibronii; no proper nuchals in $E$. dissimilis); no postnasal (vs. a postnasal present in E. bibronii); temporal scales unkeeled and smooth (vs. scales keeled in $E$. bibronii, E. dissimilis and E. novemcarinata); three or four short, blunt or less pointed lobules anteriorly (vs. 2 or 3 long, pointed in $E$. bibronii and $E$. novemcarinata; 3 or 4 long, pointed in $E$. dissimilis); dorsal scales with five feeble keels (vs. 5 to 7 sharp keels in E. bibronii; 2 or 3 strong keels in E. dissimilis; 7 to 11 sharp keels in E. novemcarinata); 32 to 34 scales round the body ( $v s .28$ to 30 scales in E. bibronii; 34 to 38 scales in $E$. dissimilis); 17 or 18 feebly keeled lamellae beneath the IV toe (vs. 14 to 20 smooth or feebly keeled lamellae in E. bibronii; 12 to 16 smoothly keeled lamellae in E. dissimilis and 18 to 21 obtusely keeled lamellae in E. novemcarinata) (Boulenger 1890; Smith 1935; Sharma 2002).

Description: Snout short, obtuse; nostril pierced behind the vertical of the suture between the rostral and the first labial; supranasals separated (Images 9 \& 10); postnasal absent (Image 7); prefrontals just touching one another (Images 9 \& 10); anterior loreal higher than long, about half the size of the posterior (Image 7); lower eyelid with an undivided transparent disc (Image 8); fronto-nasal a little broader than long in contact with the rostral and frontal; frontal a little shorter than the frontoparietals and interparietal together, in contact with the second supraocular only (Image 10); four supraoculars, second largest (Image 10); six supraciliaries; frontoparietals distinct, slightly shorter than the interparietal, which entirely separates the parietals; a pair of unkeeled nuchals present (Image 4 \& 11); temporal scales unkeeled (Image 6); ear opening triangular from one angle and subcircular from other, a little larger than a lateral scale, with four short, blunt lobules anteriorly (Image 5 \& 6); dorsal scales with three prominent and two less prominent feeble keels (quinquecarinate) (Image 13 \& 13a); 33 scales round the mid body, dorsal scales the largest; digits long, with feebly keeled lamellae and the fourth toe with 17 lamellae (Image 12). The specimen measured 


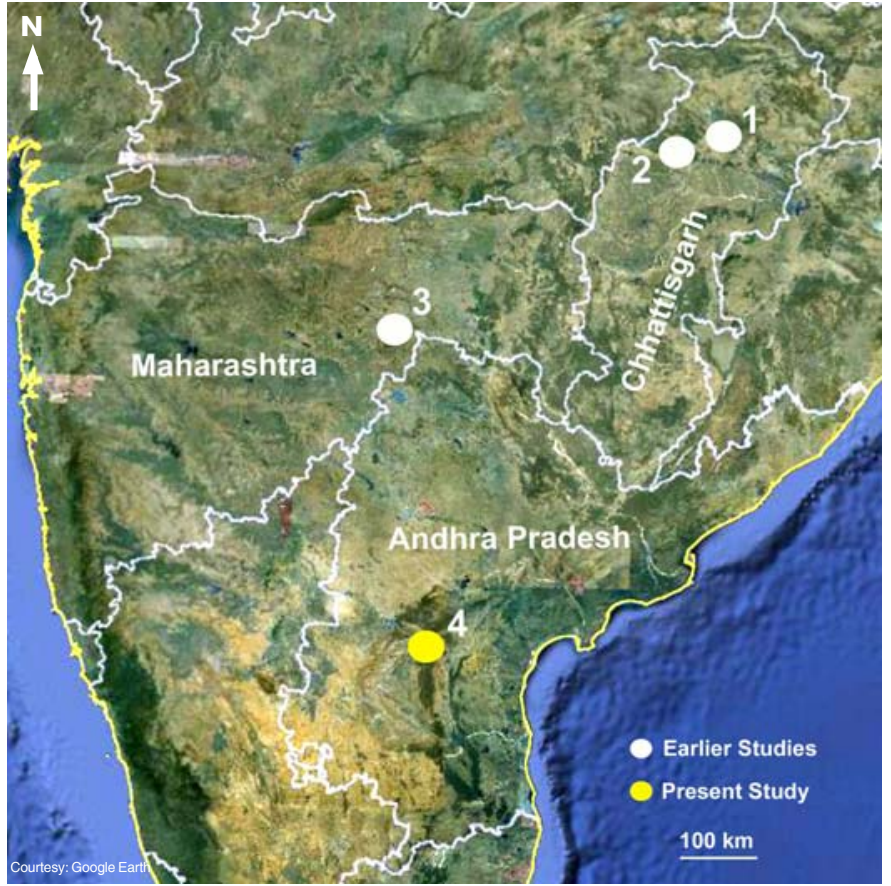

Image 1. Satellite image showing distribution of Eutropis innotata (Blanford, 1870) in three Indian states viz., 1 - Korba $\left(22^{\circ} 20^{\prime} \mathrm{N} \& 8^{\circ} 2^{\circ} 41^{\prime} \mathrm{E}\right)$; 2 - Bilaspur $\left(22^{\circ} 05^{\prime} \mathrm{N} \& 8^{\circ} 2^{\circ} \mathrm{O}{ }^{\prime} \mathrm{E}\right)$ (Chhattisgarh); 3 - Penganga Valley (19012'N \& $\left.77^{\circ} 19^{\prime} \mathrm{E}\right)$ (Maharashtra); 4 - GBM

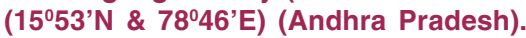

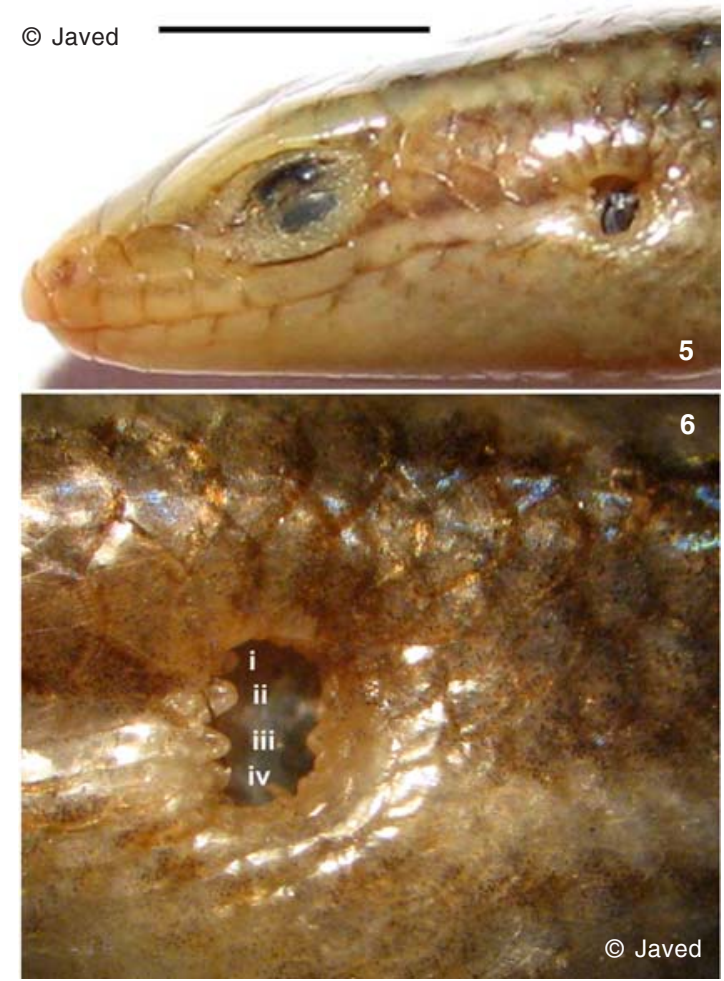

Images 5-6. Eutropis innotata. (Scale $5 \mathrm{~mm}$ ).

5 - Lateral aspect of head and neck showing undivided transparent disc in lower eye lid and triangular ear opening; 6 - Lateral aspect of ear region showing subcircular (Smith 1935) ear opening from different angle, 4 small blunt lobules and unkeeled temporal scales.
2

(C) Javed
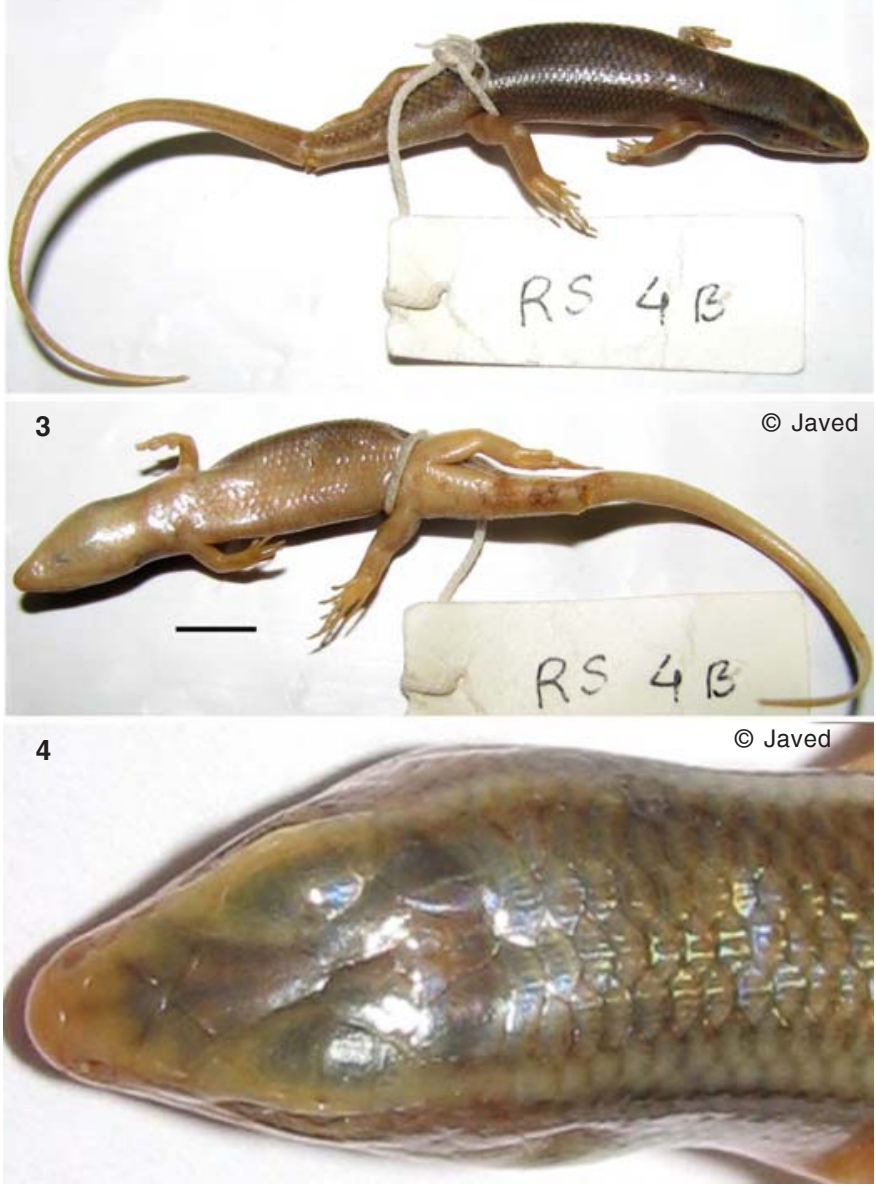

Images 2-4. Eutropis innotata. (Scale $5 \mathrm{~mm}$ ).

2 - Dorsal aspect; 3 - Ventral aspect; 4 - Dorsal aspect, head and neck close up.

$46 \mathrm{~mm}$ in snout-vent and $69 \mathrm{~mm}$ in tail length (Image $2 \& 3$ ).

Overall colouration of the skink was light golden brown, dorsal side without vertebral markings or streaks. A black dorso-lateral stripe between the eyes and base of the tail present, and the same was bordered by white line, which gradually faded posteriorly. Ventrum of the specimen was yellowish-white.

The present specimen was collected from dry leaf litter, and the area had mixed dry deciduous forest with patches of scrubs (Champion \& Seth 1968). The area experiences greater variations in temperature; maximum of $45^{\circ} \mathrm{C}$ during May and $8^{\circ} \mathrm{C}$ in December, and the locality receives about 900-1000 $\mathrm{mm}$ rainfall annually. Blanford (1870) discovered Euprepes innotatus (= Eutropis innotata) from Penganga Valley (Yavatmal District, Maharashtra) in south east Berar region. Boulenger (1887) mentioned that Blanford collected specimen of Mabuia innotata (= Eutropis innotata) from Godavari Valley, central India (part of Maharashtra). Later, he reported its occurrence from Penganga Valley (now in Yavatmal District, Maharashtra) in south east Berar region. Smith (1935) and Sharma (2002) reported Mabuya innotata (= Eutropis innotata) from south east Berar, Koba (= Korba) and Bilaspur in central province Madhya Pradesh (now Chhattisgarh), Maharashtra.

Hitherto this is the first and the only specimen of Eutropis innotata (Blanford 1870) collected from Andhra Pradesh. The diagnosis of our specimen matches well with the description provided by Boulenger (1890), Smith (1935), and Sharma 


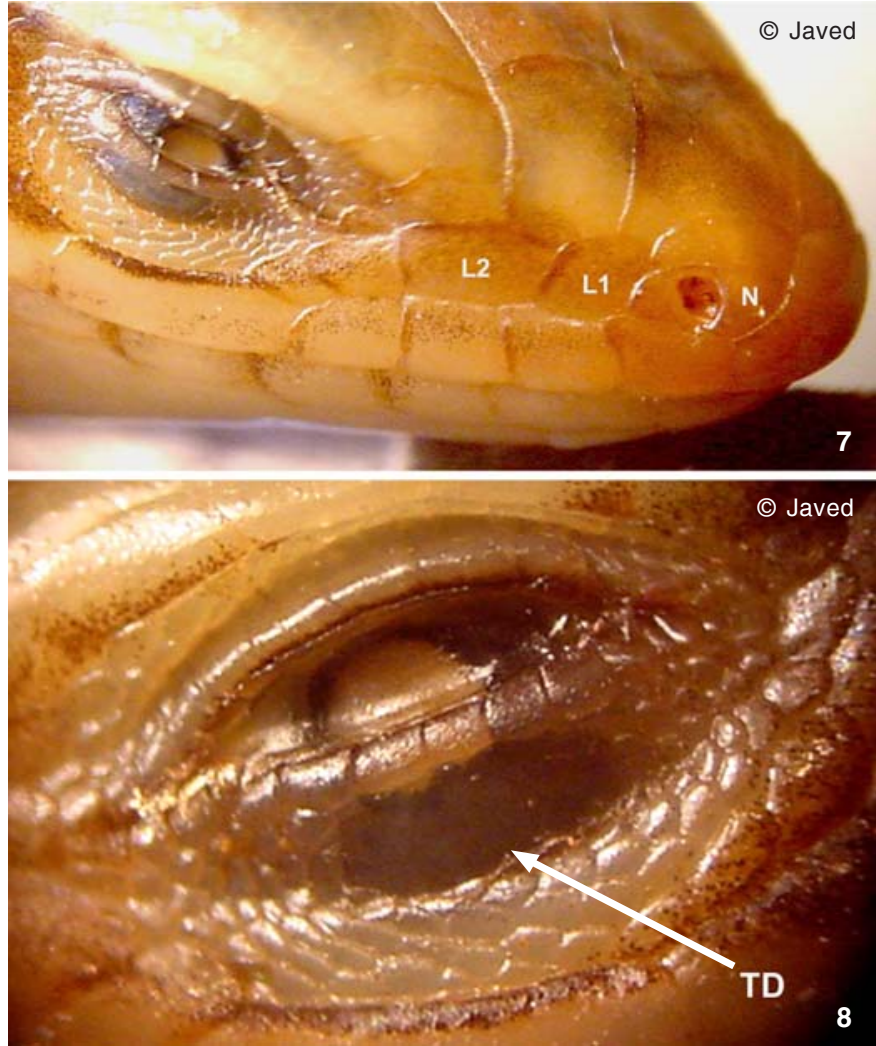

Images 7-8. Eutropis innotata.

7 - Lateral aspect of head showing eye with undivided transparent disc in lower eye lid, loreals (L1 \& L2), nasal (N) and no postnasal; 8 - Lateral aspect of eye close up showing undivided transparent disc (TD) in lower eye lid.

\section{(2002).}

The distinguishing characters and key to the known species (from peninsular India) of the genus Eutropis having lower eyelid with undivided, more or less, transparent disc is as given below:

28 to 30 scales round the mid-body; dorsals with 5 to 7 keels E. bibronii (Gray, 1839). 34 to 38 scales round the mid body: dorsals with 2 or 3 strong keels ...................................... E. dissimilis (Hallowell, 1857). 32 to 34 scales round the mid body; dorsals feebly quinquecarinate ....................... E. innotata (Blanford, 1870). 32 to 34 scales round the mid body; dorsals with 7 to 11 keels E. novemcarinata (Anderson, 1871).

\section{References}

Bauer, A.M. (2003). On the identity of Lacerta punctata Linnaeus, 1758 , the type species of the genus Euprepis Wagler, 1830, and the generic assignment of Afro-Malagasy skinks. African Journal of Herpetology 52: 1-7.

Blanford, W.T. (1870). Notes on some Reptilia and Amphibia from Central India. Journal of the Asiatic Society of Bengal 39: 335376.

Boulenger, G.A. (1887). Catalogue of the Lizards in the British Museum (Nat. Hist.) III. Lacertidae, Gerrhosauridae, Scincidae, Anelytropsidae, Dibamidae, Chamaeleontidae. Taylor \& Francies, London, 575pp.

Boulenger, G.A. (1890). The Fauna of British India, Including Ceylon and Burma. Reptilia and Batrachia. Taylor \& Francis, London, xviii, $541 \mathrm{pp}$

Champion, H.G. \& S.K. Seth (1968). A revised survey of the Forestry Types of India. Government of India, Delhi, 404pp.
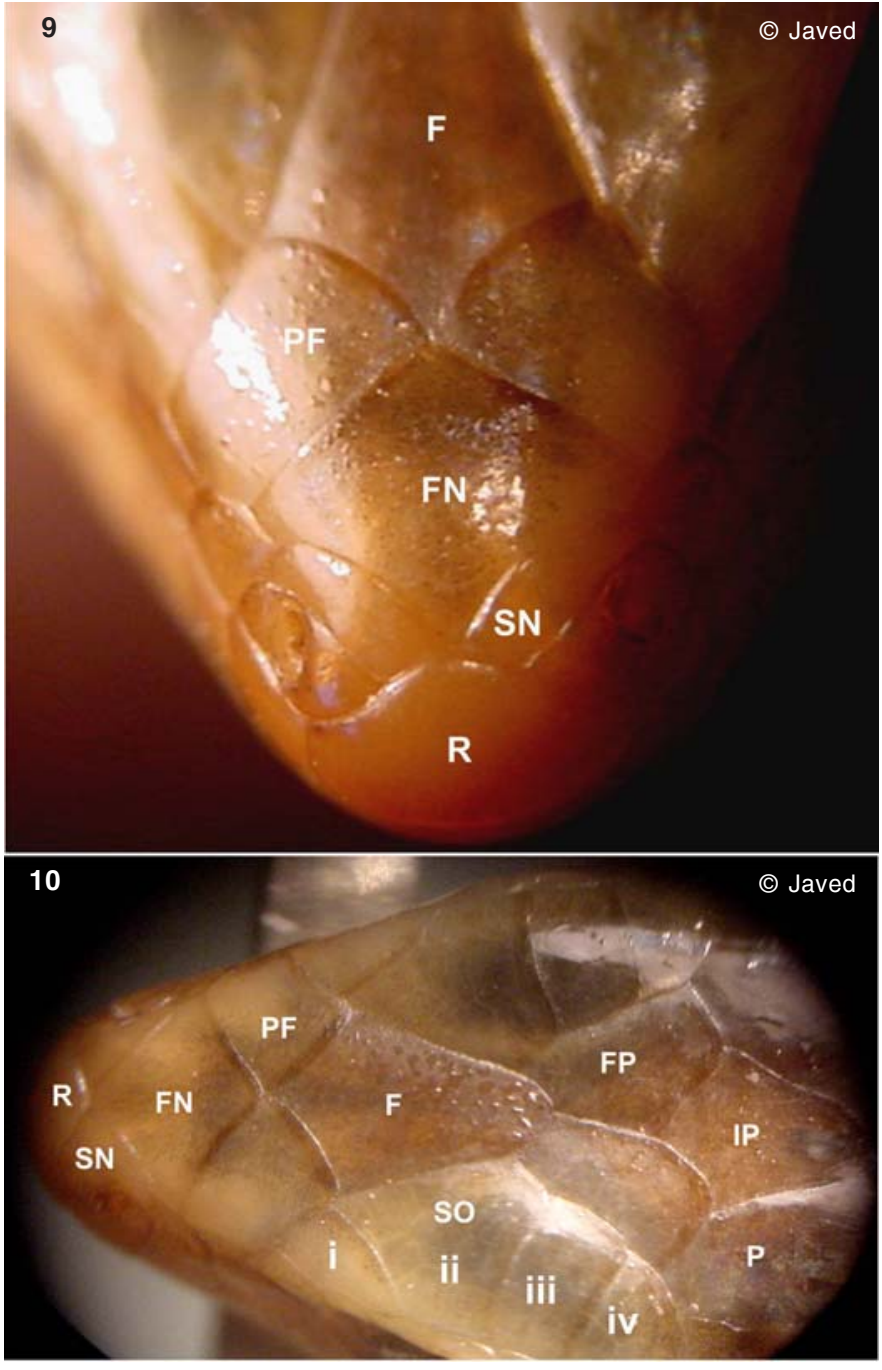

Images 9-10. Eutropis innotata.

9 - Dorsal aspect of snout showing rostral (R), supranasals (SN), fronto-nasal (FN), prefrontal (PF) and frontal (F); 10 - Dorsal aspect of head showing rostral (R), supranasals ( $\mathrm{SN})$, frontonasal (FN), prefrontals (PF), frontal (F), 4 supraoculars (SO), fronto-parietals (FP), interparietal (IP) and parietals (P).

Chandra, K. \& P.U. Gajbe (2005). An inventory of Herpetofauna of Madhya Pradesh and Chhattisgarh. Zoos' Print Journal 20(3): 1812-1819.

Das, I. (1996). Biogeography of the Reptiles of South Asia. Krieger Publishing Company, Malabar, Florida. 16 pl.+vii+87pp.

Mausfeld, P., A. Schmitz, W. Bohme, B. Misof, D. Vrcibradic \& C.F.D. Rocha (2002). Phylogenetic affinities of Mabuya atlantica Schmidt, 1945, endemic to the Atlantic Ocean Archipelago of Fernando de Noronha (Brazil): necessity of partitioning the genus Mabuya Fitzinger, 1826 (Scincidae: Lygosominae). Zoologischer Anzeiger 241: 281-293.

Molur, S. \& S. Walker (eds.) (1998). Reptiles of India. Biodiversity Conservation Prioritisation Project (BCPP) India, Endangered Species Project - Conservation Assessment and Management Plan (C.A.M.P.) workshops. Zoo Outreach Organisation \& CBSG, India, Coimbatore, India, 175pp.

Rao, K.T., H.V. Ghate, M. Sudhakar, S.M.M. Javed \& I.S.R. Krishna (2005). A Herpetofauna of Nallamalai Hills, Eastern Ghats, Andhra Pradesh, with eleven new records from the region including ten new records for the State. Zoos' Print Journal 20(1): 1737-1740 + Web supplement 1737 .

Sanyal, D.P., B.D. Gupta \& N.C. Gayen (1993). Reptilia, State Fauna series 5. Fauna of Andhra Pradesh, Part - I. Zoological Survey of 


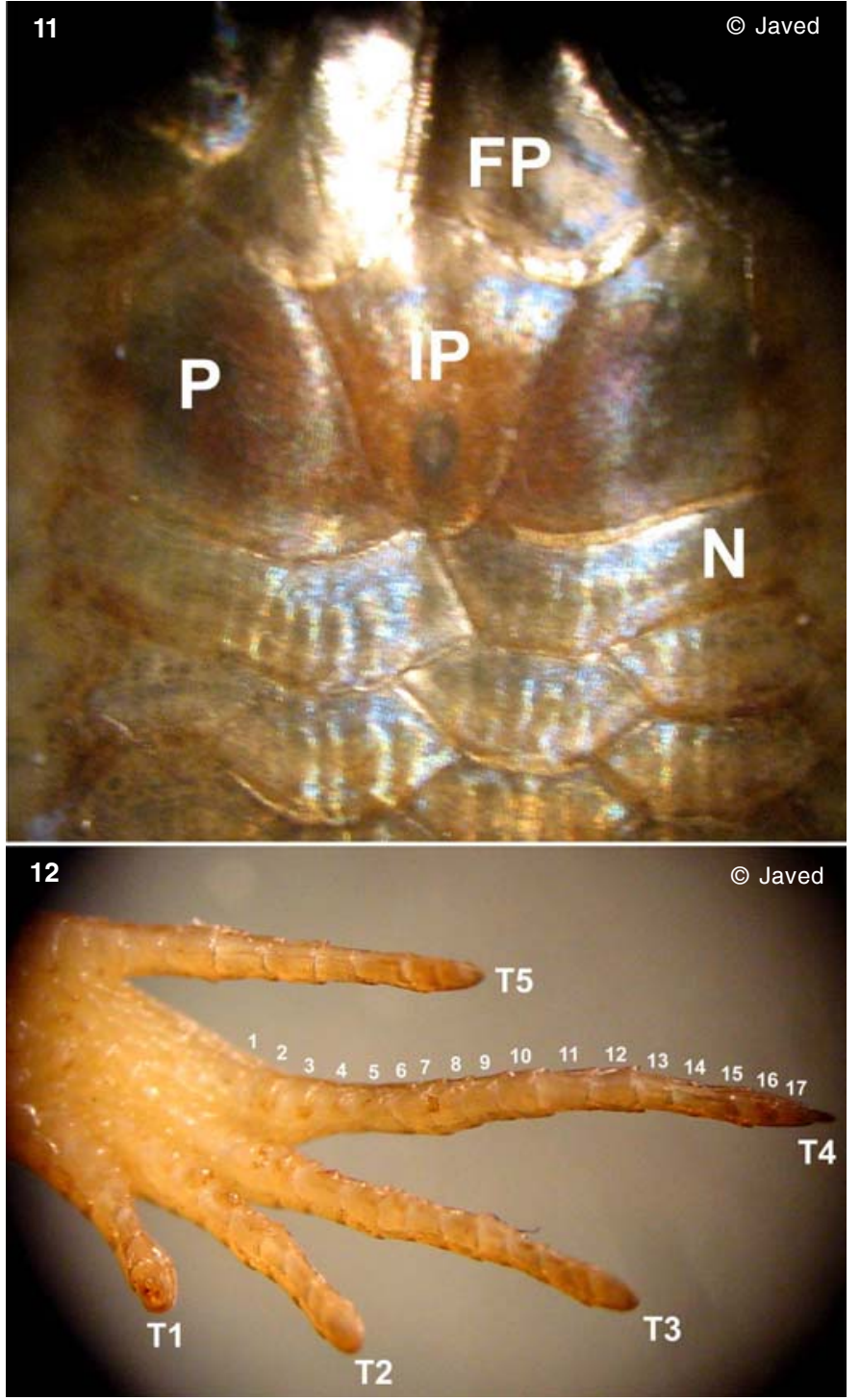

Images 11-12. Eutropis innotata.

11 - Dorsal aspect of nape showing fronto-parietals (FP), interparietal (IP), parietals (P) and nuchals (N); 12 - Ventral aspect of hind-limb showing 5 toes with feebly keeled lamellae beneath.

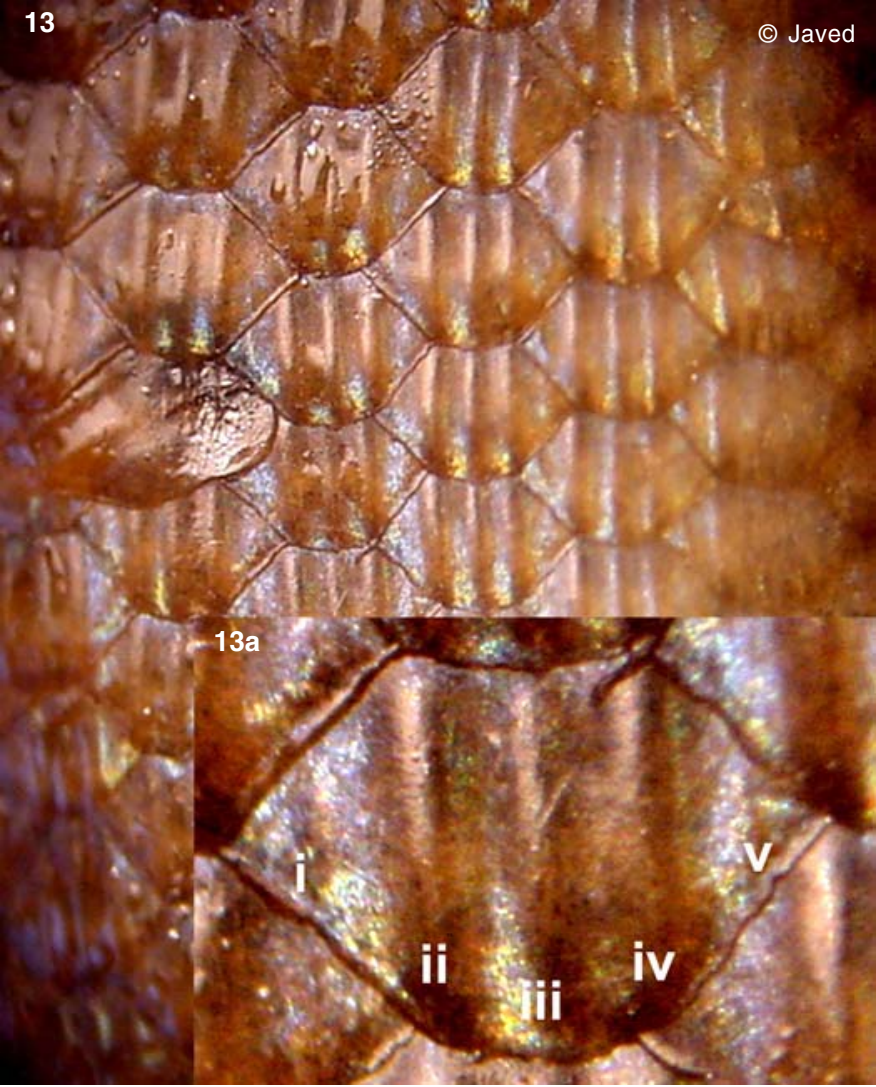

Images 13 (with inset 13a). Eutropis innotata.

Dorsal aspect of trunk showing scales with 5 feeble keels (feeble quinquecarinate) and inset showing close up of keels (see numbering).

India, Calcutta, 1-63pp.

Sharma, R.C. (2002). Fauna of India, Reptilia, Vol. - II, Sauria. Zoological Survey of India, Calcutta, 430pp.

Smith, M.A. (1935). Fauna of British India including Ceylon and Burma. Reptila and Amphibia, volume II, Sauria. Today and Tomorrow's Printers \& Publishers, New Delhi, Indian Reprint 1974, 440pp.

Srinivasulu, C., B. Srinivasulu \& C.A.N. Rao (2005). Present status of Eutropis nagarjuni (Sharma, 1969) (Reptilia: Scincidae) - An endemic skink from Andhra Pradesh India. Zoos' Print Journal 20(5): 1865-1866+Web supplement $1865 \mathrm{i}$.

Srinivasulu, C. \& I. Das (2008). The Herpetofauna of Nallamala Hills, Eastern Ghats, India: An Annotated Checklist, With Remarks on Nomenclature, Taxonomy, Habitat Use, Adaptive Types and Biogeography. Asiatic Herpetological Research 11: 110-131. 